\title{
Locally Grown, Natural Ingredients? The Isotope Ratio Can Reveal a Lot!
}

\author{
Joël S. Rossier*, Valérie Maury, and Elmar Pfammatter
}

\begin{abstract}
This communication gives an overview of selected isotope analyses applied to food authenticity assessment. Different isotope ratio detection technologies such as isotope ratio mass spectrometry (IRMS) and cavity ring down spectroscopy (CRDS) are briefly described. It will be explained how $\delta^{18} \mathrm{O}$ of water contained in fruits and vegetables can be used to assess their country of production. It will be explained why asparagus grown in Valais, in the centre of the Alps carries much less heavy water than asparagus grown closer to the sea coast. On the other hand, the use of $\delta^{13} \mathrm{C}$ can reveal whether a product is natural or adulterated. Applications including honey or sparkling wine adulteration detection will be briefly presented.
\end{abstract}

Keywords: Authentication · Cavity ring down spectroscopy (CRDS) · Geographical origin · Isotope ratio mass spectrometry IRMS - Natural/artificial ingredients

\section{Introduction}

In parallel with the increasing globalization of the food market, food traceability is receiving a steady growing interest from the consumer. Mad cow disease, the horse meat scandal or more recently, the Fukushima nuclear plant issue reinforce the desire of the population to understand where and how the food is produced. This concern has led to the multiplication of labels which have recently appeared in the commercialization of food products. Some labels have been issued with the help of governmental entities, for example in Switzerland 'Appellation d'Origine Contrôlée' (AOC) (i.e. controlled designation of origin), from producer associations 'Appellation d'Origine Protégée' (AOP) (i.e. protected designation of origin) or by private distributers like 'de la Région' (e.g. local food) or 'Natura Beef', etc. Whatever the entity issuing the label, the consumer expects that the product's origin or means of production respects the claims on the label. In reality, as long as someone is ready to pay more for 'locally grown' products, dishonest producers or distributors may try to deceive customers in order to increase illegally their revenue. As long as it is not possible to control the authenticity, some merchants will take full

\footnotetext{
${ }^{*}$ Correspondence: Dr. J. S. Rossier

Service de la consommation et des affaires

vétérinaires (SCAV)

Rue Pré d'Amédée 2

$\mathrm{CH}-1950$ Sion

E-mail: joel.rossier@admin.vs.ch
}

advantage. Food law in most countries has integrated the fact that the customer should not be misled and that doing so would constitute a non-conformity punished by administrative and/or penal measures.

In fact, law enforcement is only possible if there is a means of control accessible to food control authorities. Different and complementary ways are possible to achieve this goal; in most cases, a certification of the product/process will be issued by an independent and private organization with paper work that accompanies the product throughout the transport chain until the product is delivered. For value-added products, GPS or RFID tags are often added to prove to the customer that the traceability has been recorded all along the transport chain. These means are of course important and give a certain value to the label but it fails to guarantee that no paper exchange has occurred maliciously with the purpose of mislabelling the product.

\subsection{Locally Grown Guaranteed}

If it is possible to falsify papers or certificates, it is much more challenging and costly to change the composition of the product in order to mislead a consumer on the origin or the process of the production of the corresponding goods. Most food stuffs are composed of significant parts of water and carbon. Both of these constituents are composed of different stable isotopes which can be used as fingerprints to assess the veracity of the labelling, both in terms of geographical origin and/or composition. Water is constituted of hydrogen and oxygen, both of which occur in different isotopic forms in nature; while more than $99.9 \%$ of the water molecules are composed of $\mathrm{H}_{2} \mathrm{O}$, some molecules of water occur in a form of heavy water com- posed of $\mathrm{DHO}$ or $\mathrm{H}_{2}{ }^{18} \mathrm{O}$. The parameters for this measurement being expressed as $\delta \mathrm{D}$ or $\delta^{18} \mathrm{O}$-ratios, respectively, and defined in Eqn. (1) (e.g. for $\left.\delta^{18} \mathrm{O}\right)$.

$$
\left.\delta^{18} O=\left(\frac{\left(\frac{(18 O}{16 O}\right)_{\text {sample }}}{\left({ }^{18} \mathrm{O} O\right.}\right)_{\text {standard }}-1\right) * 1000 \%(1)
$$

The standard in Eqn. (1) $\left({ }^{18} \mathrm{O} /{ }^{16} \mathrm{O}\right)$ expresses the mean value of all the water on the earth, named Vienna Standard Mean Ocean Water (V-SMOW) and it has a value of 2005.20.[1]

The relative abundance of heavy atoms in a product has been observed to be higher when the product has been grown close to the coast and/or in a warmer climate. Indeed as can be seen from Fig. 1a, a gradient of heavy water can be measured in precipitation across Europa (from Spain to Russia).

Another significant contributor is the evaporation process in plants which increases the concentration of heavy constituents such as DHO or $\mathrm{H}_{2}{ }^{18} \mathrm{O}$ since light $\mathrm{H}_{2} \mathrm{O}$ will transpire and/or evaporate preferentially (Fig. 1b). In Europe, the regions generally producing fruit and vegetables for export to Switzerland include both characteristics of being close to the sea and to be in a warmer climatic region. These regions are mainly located in Spain, south of France, and Italy. Therefore, both effects shown in Fig. 1a and b provide a good signature of heavy water constituent in the products (more positive $\delta \mathrm{D}$ or $\delta^{18} \mathrm{O}$ ). On the other hand, products grown in the mountains such as the Alps have a reduced distribution of heavy water (more negative $\delta \mathrm{D}$ or $\delta^{18} \mathrm{O}$ ); altitude is indeed another element of discrimination between heavy and 


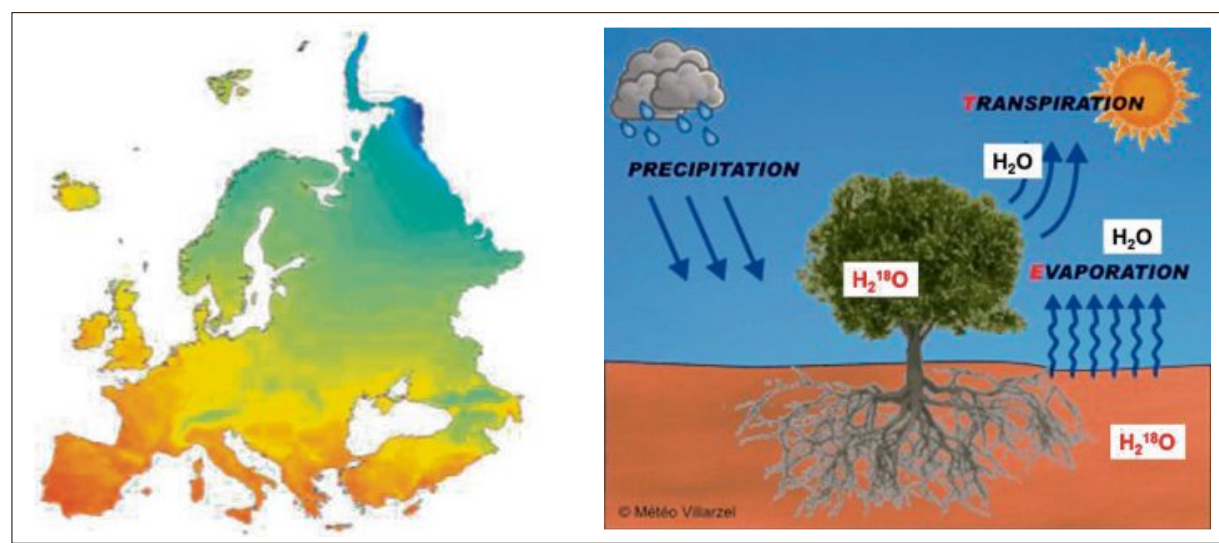

Fig. 1. a) Geographical dependence of water isotope values from heavier (in orange) to lighter (in blue) with $\delta D$ positive to negative values, respectively (Isoscape maps courtesy of Prof. G. J. Bowen, ref. [2]) (Remark: the values of $\delta \mathrm{D}$ and $\delta^{18} \mathrm{O}$ are correlated). b) Heat effect on water isotope pre-concentration in plants through enhanced evaporation of light water. Scheme adapted from Meteo Villarzel, http://www.boock.ch/meteo/evapotranspiration_48h.php, courtesy of Aubert Pierre-André. light water, the latter being better able to pass by the Alps in the cloud layer than the heavier isotopes. In Valais area for instance, the $\delta \mathrm{D}$ or $\delta^{18} \mathrm{O}$ of water in fruits, vegetables or wine is significantly different from that close to the sea and in warmer climates for instance. With modern technics based on isotopic ratio mass spectrometry (IRMS) or with optical IR cavity ring down spectroscopy (CRDS) techniques, it is possible to detect the fine differences in the isotope water composition of several products such as fruits, vegetables, wine or fish for instance and to determine whether a label of origin is misleading or not. ${ }^{[1,3]}$

\subsection{Natural Ingredient \\ Authentication}

Carbon is present in the form of different stable isotopes on the earth. If $99 \%$ carbon has a molecular weight of 12 , a fraction of the carbon occurs as ${ }^{13} \mathrm{C}$; the abundance ratio between ${ }^{13} \mathrm{C}$ and ${ }^{12} \mathrm{C}$ is expressed as $\delta^{13} \mathrm{C}$ as shown in Eqn. (2).

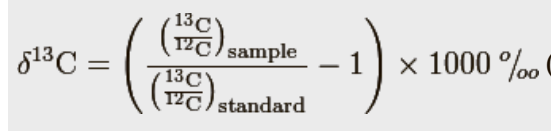

The standard presented in Eqn. (2) has been chosen by convention to be a rock from California, named Pee Dee Belemnite (PDB), This material had an anomalously high ${ }^{13} \mathrm{C} /{ }^{12} \mathrm{C}$ ratio $(0.0112372)$, and was established as the $\delta^{13} \mathrm{C}$ value of zero. ${ }^{[4]}$

A product enriched with ${ }^{13} \mathrm{C}$ carbon will exhibit a more positive $\delta^{13} \mathrm{C}$ value whereas one with a lower ${ }^{13} \mathrm{C}$ concentration will present a more negative one.

Carbon found in plants originates from the atmosphere and is fixed into the organisms through different photosynthetic mechanisms. Photosynthesis in most plants follows one of two main photosynthetic pathways (C3 versus C4) and plants exhibiting these pathways have been shown to differ in the carbon isotope ratios of their products. ${ }^{[5]}$ Sugar cane follows the C4 photosynthesis metabolism, meaning that the first organic molecule formed after uptake of atmospheric $\mathrm{CO}_{2}$ is composed of four atoms of carbon. Flowers or sugar beet, however, exhibit C3 photosynthesis, in which the first organic molecules are composed of three atoms of carbon. Typical $\delta^{13} \mathrm{C}$ values for $\mathrm{C} 3$ plants range from -25 to -30 whereas they range from -12 to -16 for $\mathrm{C} 4$ plants as can be seen in Fig. 2.

Furthermore, carbon originating from petroleum sources has a much lower $\delta^{13} \mathrm{C}$ value, lower than -30 . It is therefore possible to detect the presence of plant components that originate from a $\mathrm{C} 3$ or $\mathrm{C} 4$ plant or chemical synthesis and to assess mislabelling as explained in section 3 .

\section{Material and Methods}

Two main technologies are currently used to analyse isotope ratios. First of all, isotopic ratio mass spectroscopy (IRMS) uses a mass spectrometer detector to detect the ratio of $\mathrm{CO}_{2}$ in different forms $\left(\mathrm{CO}_{2} /{ }^{13} \mathrm{CO}_{2} / \mathrm{C}^{18} \mathrm{OO}\right.$ with $\mathrm{m} / \mathrm{z} \quad 44 / 45 / 46$ resp.) as described earlier. ${ }^{[1,3]}$ For sparkling drinks, the gas is injected and detected after a short equilibrium with a standard reference $\mathrm{CO}_{2}$. For heavy water $\left(\mathrm{H}_{2}{ }^{18} \mathrm{O}\right)$ a small liquid sample is equilibrated in a gasbench device (Eqn. (3)) with a standard reference $\mathrm{CO}_{2}$ for $18 \mathrm{~h}$ and the resulting gas is injected into the mass spectrometer.

$$
\mathrm{C}^{16} \mathrm{O}^{16} \mathrm{O}+\mathrm{H}_{2}{ }^{18} \mathrm{O} \leftrightharpoons \mathrm{C}^{16} \mathrm{O}^{18} \mathrm{O}+\mathrm{H}_{2}{ }^{16} \mathrm{O}
$$

For the detection of ${ }^{13} \mathrm{C}$ in a solid sample, a few mg of material are pyrolysed with a catalyser at $1400{ }^{\circ} \mathrm{C}$ and the $\mathrm{CO}_{2}$ and the $\mathrm{H}_{2} \mathrm{O}$ vapours are sent to the detector.

The second principle is purely optical and based on the IR absorption capability of $\mathrm{CO}_{2}$ and $\mathrm{H}_{2} \mathrm{O}$. Carbonate and water will absorb at slightly different wavelengths whether they are composed of heavy or light elements. Picarro Inc has developed a unique high-resolution IR spectrometer based on cavity ring-down spectroscopy (CRDS) enabling the simultaneous detection of $\mathrm{D}$ and ${ }^{13} \mathrm{C}$ after sample pyrolysis. CRDS overcomes any sensitivity limitation by using an effective pathlength of

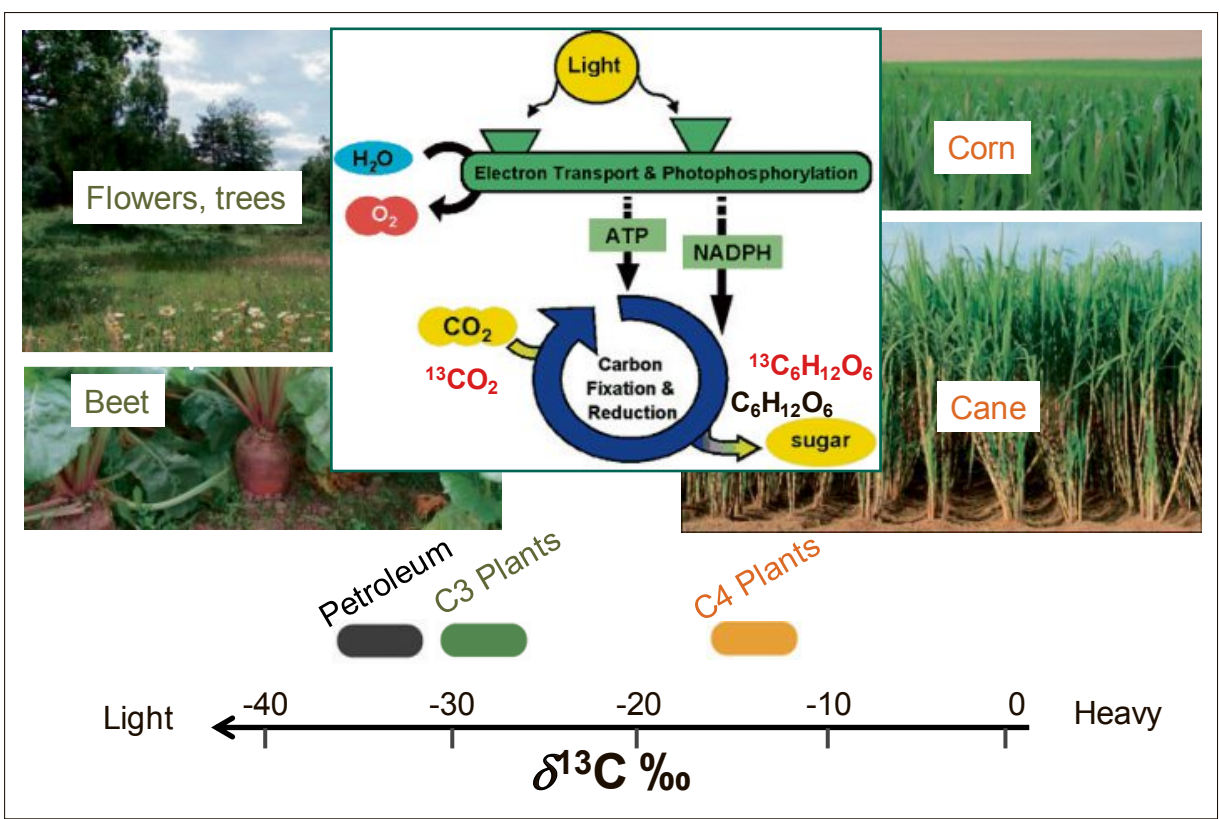

Fig. 2. Typical $\delta^{13} \mathrm{C}$ values of petroleum, C3 and C4 plants, the latter two differing by their specific metabolic photosynthesis mechanisms. 
many kilometres. It enables gases to be monitored in seconds or less at the parts per billion level, and some gases at the parts per trillion level. ${ }^{[4,6]}$

\section{Selected Examples of Isotope Analyses in the Domain of Food Authenticity}

\subsection{Assessment of the Origin of Fruits and Vegetables Grown Locally.}

In this section, different applications of isotope analysis will be briefly presented, starting with vegetables grown in Valais, a Canton of Switzerland. Since Valais is surrounded by the Alps, most of its ground water is impoverished in heavy elements and therefore its $\delta^{18} \mathrm{O}$ value is significantly lower than that determined for the other producing countries listed in Fig. 3; in this case, $\delta^{18} \mathrm{O}$ measured by IRMS is a good tracer of locally grown asparagus.

Nowadays, this traceability technique has been applied successfully to different products including apricots and wine. Furthermore, this technique is very useful to detect the origin of lake fish; indeed, the $\delta^{18} \mathrm{O}$ value of water contained in the fish correlates very well with the that of the corresponding lake. Since lakes from different altitudes have a different $\delta^{18} \mathrm{O}$ values it is possible to control labels as fish from lakes Léman or Neuchâtel (Switzerland) for instance. ${ }^{[1]}$

\subsection{Assessment of the Natural Origin of Ingredients}

The analysis of the $\delta^{13} \mathrm{C}$ value can reveal whether a product is natural or adulterated as presented in Fig. 2. A few applications of this capacity are presented.

\subsubsection{Natural or Artificial $\mathrm{CO}_{2}$ in Sparkling Water}

The measurement of $\delta^{13} \mathrm{C}$ provides information on components of non-organic origin of products such as gas in mineral water. On the market, two different types of mineral water can be commercialized containing dissolved carbonic acid. Natural $\mathrm{CO}_{2}$ was trapped millions of years ago in ground water cavities in volcanic regions where mineral water sources are captured and bottled without further treatment. This sparkling water can be commercialized with the label 'naturally sparkling'. On the other hand, artificial $\mathrm{CO}_{2}$ (byproduct of oil cracking) may be added to still water during bottling to obtain a gasified mineral water, which cannot claim to be 'naturally sparkling'. A simple analysis of $\delta^{13} \mathrm{C}$ easily permits both products to be distinguished since oil-based $\mathrm{CO}_{2}$ has a typical $\delta^{13} \mathrm{C}$ value of -37 whereas 'natural' $\mathrm{CO}_{2}$ trapped

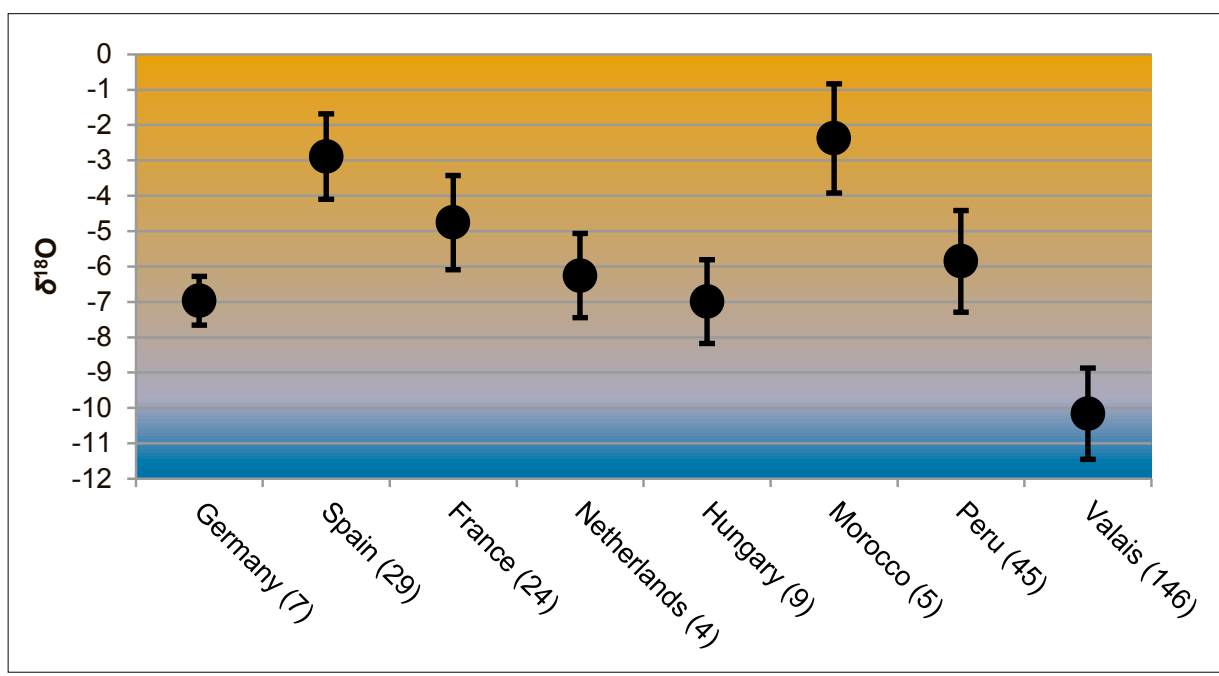

Fig. 3. $\delta^{18} \mathrm{O}$ value of water extracted from white asparagus cultivated in different countries; the lower value obtained for Valais enables retail mislabelling to be tracked.

underground is ${ }^{13} \mathrm{C}$-enriched and displays a typical $\delta^{13} \mathrm{C}$ value of -5 . It is therefore easy to screen many different sparkling waters and compare the declaration with the true origin.

\subsubsection{Natural or Artificial $\mathrm{CO}_{2}$ in Sparkling Wines}

Sparkling wines are of course good candidates for potential fraud. Wine obtained with the so-called 'méthode traditionelle' are costly to prepare and necessitate several months of in-bottle fermentation followed by sequential manual handling which renders the product so expensive. At the other end of the scale, bulk production lowers costs to produce sparkling wine with the help of artificial $\mathrm{CO}_{2}$ addition (Fig. 4). Such products cannot be compared and it is important to be able to control that products labelled with 'méthode traditionelle' really originate from fermentation in the bottle. For this purpose, the sugar content of the wine and $\mathrm{CO}_{2}$ are measured independently and their $\delta^{13} \mathrm{C}$ values compared. If the $\delta^{13} \mathrm{C}$ values differ significantly, mislabelling can be established. Recently, two non-conform sparkling wines labelled 'traditional' were measured to have a difference in $\delta^{13} C$ value of $>9$ units which constitutes a falsification for the consumer. A detailed description of the analysis of the isotope ratio in sparkling wine can be found elsewhere in this issue. ${ }^{[4]}$

Similarly, it is possible to distinguish whether further constituents such as flavours, colorants or sweeteners are artificial, i.e. synthetized, or of natural origin. For example artificial and natural caffeine or vanillin are achiral molecules, which means that the natural and artificial moleculaes cannot be distinguished by high resolution chiral chromatography, the method of choice for detecting synthetic flavour additives. Therefore the only analytical method to detect the addition of synthetic caffeine or vanillin is isotope analysis. ${ }^{[7]}$

\subsubsection{Natural Product Authentication and Adulteration; Addition of Sugar to Honey}

A classical fraud is the adulteration of honey with sugar in order to increase the mass of product by feeding the bees with sugar instead of pollen. The incentive is high since sugar solutions are 5 to 10 times less expensive than honey. Solutions of corn syrup are readily available for the beekeeper since it is only forbidden to feed the bees during the season of honey production, but is allowed the rest of the year. A comparison of the $\delta^{13} \mathrm{C}$ values of honey protein and sugar will reveal a fraud. If both protein and sugar $\delta^{13} \mathrm{C}$ values differ by more than 1.2 , honey has been adulterated and should be relabelled or withdrawn from the market. ${ }^{[8]}$

\subsubsection{Tell me what you eat and I will tell you who you are}

Isotopic ratio not only applies to plants or synthetic products but also to animals

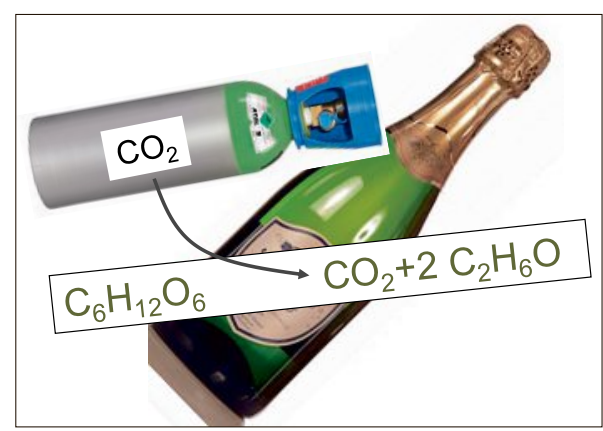

Fig. 4. Sparkling wine: does $\mathrm{CO}_{2}$ originate from in-bottle fermentation or from an addition of artificial $\mathrm{CO}_{2}$ during the bottling? $\delta^{13} \mathrm{C}$ value comparison of sugar and $\mathrm{CO}_{2}$ clearly gives the answer. 
such as fish or chicken for instance. The flesh of animals with different diets will have different $\delta^{13} C$ values. ${ }^{[9]}$ For example, cornfed chicken, which is a costly label in some countries, carry the signature of corn, a plant of the $\mathrm{C} 4$ metabolism; therefore, the meat of such chicken exhibits a typical value of -17 whereas wheat-fed chicken meat shows a $\delta^{13} \mathrm{C}$ value around -26 . Such a difference is significant and very consistent since industrial farms do not vary their feeding procedure and/or feed sources. In a similar way, fishes can be distinguished by their means of production. For instance, a wild fish from the ocean will eat plankton whereas the same species of fish in a fish farm will be fed with industrial food composed of colza oil pressed together with fish flour; both diets lead to significantly different $\delta^{13} C$ values enabling to control the truth of vendor allegations.

\section{Conclusion}

Using both water (geographical origin) together with carbon isotope distribution (naturally or synthetic origin) enabled the efficient detection of cases of mislabelling. Examples of sparkling wine, fish, honey, apricots and asparagus illustrate the use of isotope ratio determination in routine food control. Misleading is not only a problem of consumer disrespect; it is an attitude that should be seriously fought, because if a product is mislabelled, consumer trust disappears. The problem may not only be mislabelling but a corrupted product containing mycotoxin or other poisons for instance. Therefore, countering mislabelling is more than a legal problem but a true food safety issue!

\section{Acknowledgements}

The authors would like to thank the whole SCAV team for their assistance. In particular, the authors would like to thank Laetitia Gaillard who read the manuscript and provided critical comments.

Received: December 1, 2015

[1] J. S. Rossier, V. Maury, B. de Voogd, E. Pfammatter, Chimia 2014, 68, 696.

[2] G. J. Bowen, Annu. Rev. Earth Planet. Sci. 2010, 38,161 .

[3] G. Gremaud, S. Quaile, U. Piantini, E. Pfammatter, C. Corvi, Eur. Food. Res. Technol. 2004, $219,97$.

[4] J. S. Rossier, V. Maury, L. Gaillard, E. Pfammatter, Chimia 2016, 70, 338.

[5] G. D. Farquhar, J. R. Ehleringer, K. T. Hubick, Annu. Rev. Plant Physiol. Plant Mol. Biol. 1989, 40, 503.

[6] S. A. Walker, K. Azetsu-Scott, C. Normandeau, D. E. Kelley, R. Friedrich, R. Newton, P. Schlosser, J. L. McKay, W. Abdi, E. Kerrigan, S. E. Craig, D. W. R. Wallace, Assoc. Sci. limnol. Oceanogr. 2015, 14, 31

[7] M. Bononi, G. Quaglia, F. Tateo, J. Agric. Food Chem. 2015, 63, 4777.

[8] Official AOAC Method: 978.17-1979, 'Corn and cane sugar products in honey'.

[9] D. J. Morrison, B. Dodson, C. Slater, Rapid Commun. Mass Spectrom. 2000, 14, 1321. 